\title{
Revista Brasileira de Psiquiatria chega finalmente ao Medline
}

No mês de julho recebemos a tão esperada notícia de que a RBP foi indexada no Index Medicus®/MEDLINE®, onde os nossos artigos já estão disponíveis.

Com a multiplicidade na oferta de conhecimento no mundo moderno, o gerenciamento de informação se tornou crucial. Assim, órgãos reguladores que administrem e qualifiquem as informações passaram a ser críticos. $\mathrm{Na}$ área médica, o Index Medicus e sua contraparte online nomeada MEDLINE ${ }^{\circledR}$ (Medical Literature, Analysis, and Retrieval System Online) da Biblioteca de Medicina Americana (U.S. National Library of Medicine's, National Institutes of Health do U.S. Department of Health \& Human Services) é o maior e mais renomado banco de dados em medicina, atualmente com mais de 12 milhões de referências. Depois de um ano sendo avaliada, a RBP recebeu o escore de muito bom (entre 3,4 e 3,9). A decisão de um jornal científico vir a ser indexado ou não nesse banco de dados é baseada na qualidade científica do jornal e no parecer do conselho de regentes da biblioteca (The Literature Selection Technical Review Committe). Este conselho se reúne três vezes ao ano e analisa aproximadamente 140 jornais em cada reunião. Atualmente são 4.500 jornais indexados no MEDLINE e 3.650 no Index Medicus.

Além disso, com o aprimoramento da avaliação dos programas de pós-graduação no país, tendo-se como critério essencial a relevância da produção intelectual aferida pela qualidade dos veículos científicos, a inclusão da revista em uma base internacional de dados tornou-se fundamental. Portanto, a indexação em bases de literatura internacionais, como o Index Medicus®/MEDLINE®, era um dos principais objetivos do grupo que assumiu a condução da RBP há seis anos atrás. Neste período, a RBP passou por uma ampla reestruturação, com a finalidade de dar maior visibilidade à produção científica na área de Psiquiatria do Brasil e da América Latina. Houve uma ampliação importante da participação da comunidade internacional e uma seleção rigorosa dos integrantes brasileiros e latino-americanos (com base estrita no critério de produtividade científica) na composição do corpo editorial. Focados neste objetivo, no último ano decidimos traduzir os artigos originais para o inglês. Com esta indexação, a RBP passa a ser qualificada não mais como uma revista Nacional, mas Internacional (Internacional C), pelos critérios de avaliação da Capes.

Um artigo no Index Medicus@/MEDLINE@ terá maior chance de ser encontrado, reproduzido e citado. Assim, os artigos da $\mathrm{RBP}$, incluindo artigos originais, relatos de caso, revisões, editoriais e cartas ao editor, estarão mais acessíveis para o resto do mundo. Para aqueles que acreditaram na RBP, uma outra boa notícia. A indexação é retroativa há um ano. Desta forma, os artigos publicados nos números 3 e 4 de 2002 e nos números 1 e 2 de 2003 também estarão disponíveis nestas bases de dados.

Este novo status alcançado pela RBP é em grande parte reflexo da diretriz assumida pelas diretorias recentes da Associação Brasileira de Psiquiatria (ABP) que, ao longo destes anos, entenderam que o trabalho de editoria deve ser conduzido com autonomia científica plena, sem ingerência política. Esta nova idéia foi concebida durante a presidência de Rogério Aguiar, executada de fato na de Miguel Roberto Jorge, e ganhou novo alento com o grupo atual liderado por Marco Antônio Brasil. Com eles, acreditamos ter tornado este relacionamento (de editores científicos e diretoria da ABP) um exemplo para outras revistas científicas no país que não gozam deste privilégio.

Nestes seis anos, passaram pelo atual grupo de editores outros com os quais dividimos o trabalho e iniciativas que levaram a esta nova conquista da RBP. Entre eles, destacamos Geraldo Busatto Filho, Isabel Altenfelder Bordin e Claudio Csillag entre outros. Cuidando das resenhas de livros, tivemos Eduardo Iacopone e agora Mauro Aranha e Flávio Kapczinski, trazendo o que há de mais atual na literatura científica. Paulo Dalgalarrondo e o seu investimento na seção de memória da revista permitiu o acesso a fatos e personalidades importantes da nossa história. Agradecemos também o apoio técnico das secretárias, do corpo editorial, dos pareceristas ad hocs, dos leitores, dos colegas estrangeiros, e de todos os pesquisadores que confiaram seus artigos a RBP.

Ao lado de Luiz Augusto Rohde, Rodrigo Bressan e Hermano Tavares, acreditamos estar preparados para o próximo passo: conhecermos o nosso fator de impacto medido pelo Science Citation Index do Institute for Scientific Information. Para isso, vamos precisar que nossos artigos sejam reconhecidos como de qualidade pela comunidade científica. Portanto, aproveitamos para conclamar todos os colegas a enviarem seus artigos para a RBP, e não se esquecerem de citar os artigos de qualidade que foram nela veiculados. É neste ritmo, em um trabalho conjunto com todos os profissionais envolvidos na área, que pretendemos colocar a RBP na elite das revistas científicas da Psiquiatria e da América Latina.

\author{
Euripedes C Miguel \\ Jair Mari \\ Marcos T Mercadante \\ Editores
}

